\title{
PARENTS, SOCIAL MEDIA, AND ONLINE SUPPORT: A SYSTEMATIC REVIEW OF THE LITERATURE
}

\author{
Vanessa P. Dennen, Daeun Jung, Casey Cargill and Amber Hedquist \\ Florida State University \\ Tallahassee, FL USA
}

\begin{abstract}
Much like every other aspect of contemporary life, parenting has been affected by the Internet. Parents use the Internet in a variety of ways while raising their children, including as a source of information and support. In addition to accessing static information, they engage with others in social media contexts. In this study, we present a systematic review of the research on social media use to support parenting activities, examining research trends and more substantively how parenting and social media intersect. A search of studies published between 2010-2019 yielded 70 relevant articles, classified as providing health-related support, school-related support, and general support. Findings suggest that research in this area is emergent and growing quickly, and most existing studies focus on specific instances of support. The field would benefit from underlying work to establish the prevalence, scope, and nature of parent social media support activities.
\end{abstract}

\section{KEYWORDS}

Health Information, Online Community, Parents, Scoping Review, Support, Social Media

\section{INTRODUCTION}

Parenting is a hands-on activity, but the Internet nonetheless plays a role in the contemporary parent-child relationship. Parents with questions unsurprisingly turn to search engines and their online networks for answers. For example, a study of an online community for parents, babycenter.com, found that it was frequented by parents looking for affirmation related to normative child development (Jang \& Dworkin, 2012). That behavior quite naturally extends from search engines and private online communities to social media-based ones. A 2015 survey of American parents by the Pew Research Center found that among social media users (75\% of the sample in 2015 and surely higher now), parents were likely to use social media within their friend networks to share and seek support, affirmation, and information (Duggan et al., 2015).

For parents, social media can provide online friendship, and it can also provide an outlet for being empowered by telling one's stories of parenting, as experienced by the fraught-titled mommy bloggers (Chen, 2013). An earlier review of literature found that for most parents, online engagement with other parents is a satisfying activity (Dworkin et al., 2013), although 'parents' most often means mothers in this context. Fathers have been less frequently studied and when studied less likely to express satisfaction (He \& Dworkin, 2015/2016).

\section{METHOD}

\subsection{Study Design and Research Questions}

The purpose of this study is to systematically review the existing empirical research on how parents use social media to identify the current research trends and illuminate areas that would be appropriate for future research. The research questions guiding this review are: 
1. What are the research trends related to social media use to support parenting activities?

2. How do people use social media to support parenting activities?

We draw upon Arksey and O'Malley (2005) scoping review framework to investigate this topic. They indicated that among the four reasons for conducting a scoping review, one might seek to map the range of research previously conducted on a topic and summarize that research while answering research questions of a general nature (Arksey \& O'Malley, 2005). Although there is some disagreement in the literature as to whether or not scoping reviews are a form of systematic literature review (Morris et al., 2016), based in part on the wide range of methodological rigor apparent across published scoping reviews (Pham et al., 2014; Tricco et al., 2016), in this study we apply a systematic approach to the scoping review (Peters et al., 2015).

\subsection{Sampling}

The article sampling procedure followed the PRISMA 2020 guidance for systematic reviews (Page et al., 2021). Articles were sampled via a search using Web of Science, focusing on four major journal indices (Social Science Citation Index, Science Citation Index, Arts \& Humanities Citation Index and Emerging Sources Citation Index). The Web of Science Database is frequently used as a data source for review articles (Li et al., 2018), including scoping reviews (e.g., Dennen et al., 2020). A topical search was used, based on the following parameters:

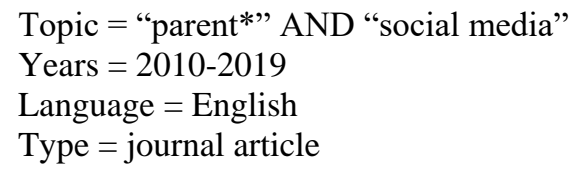

The initial search was conducted on October 3, 2019, with a secondary search conducted on March 20, 2020 focused solely on 2019 publications to identify additional articles published during late 2019 .

As shown in Figure 1, after an initial 845 articles were identified, 582 were removed during a screening for relevance. Three team members independently screened each article, and when in doubt the full article was reviewed by the full team in a meeting. In some instances, the articles were about teenagers' use of social media, and mentioned parents somewhere within the articles. These articles contained adjacent research, but did not focus on the main phenomenon we were interested in. In others, the search terms merely appeared somewhere in the article but the overall topic was not relevant, or the focus was on using social media as a research recruitment or data collection method for studies of other phenomena.

The 263 relevant articles were retrieved and reviewed independently by two team members with the third and fourth team member weighing in where discrepancies arose. In this secondary screening process, 139 non-empirical articles were removed, along with 54 articles that were empirical studies at the intersection of parents and social media but looking at other topics (e.g., how parents monitor their children's social media use and how social media mediates the parent-child relationship). The remaining 70 empirical articles all focused on some aspect of how social media is used to support parenting. References for the full sample can be found at https://studentssocialmediaschools.files.wordpress.com/2021/07/wbc2021reviewsamplereferences.pdf.

\subsection{Coding and Analysis}

The final sample of 70 studies were coded by year, country of study, data collection method(s), data sources (parents, children), and age of parents' children. Frequency distributions were created for each of these areas. Then each study was reviewed and classified into four categories:

(1) Parenting - health-related (physical, mental, and behavioral)

(2) Parenting - school-related

(3) Parenting - general support

(4) Parenting - other (articles that did not fit other categories)

Within each category, the articles were examined by research method and sub-topic to identify areas where most research is focused. 


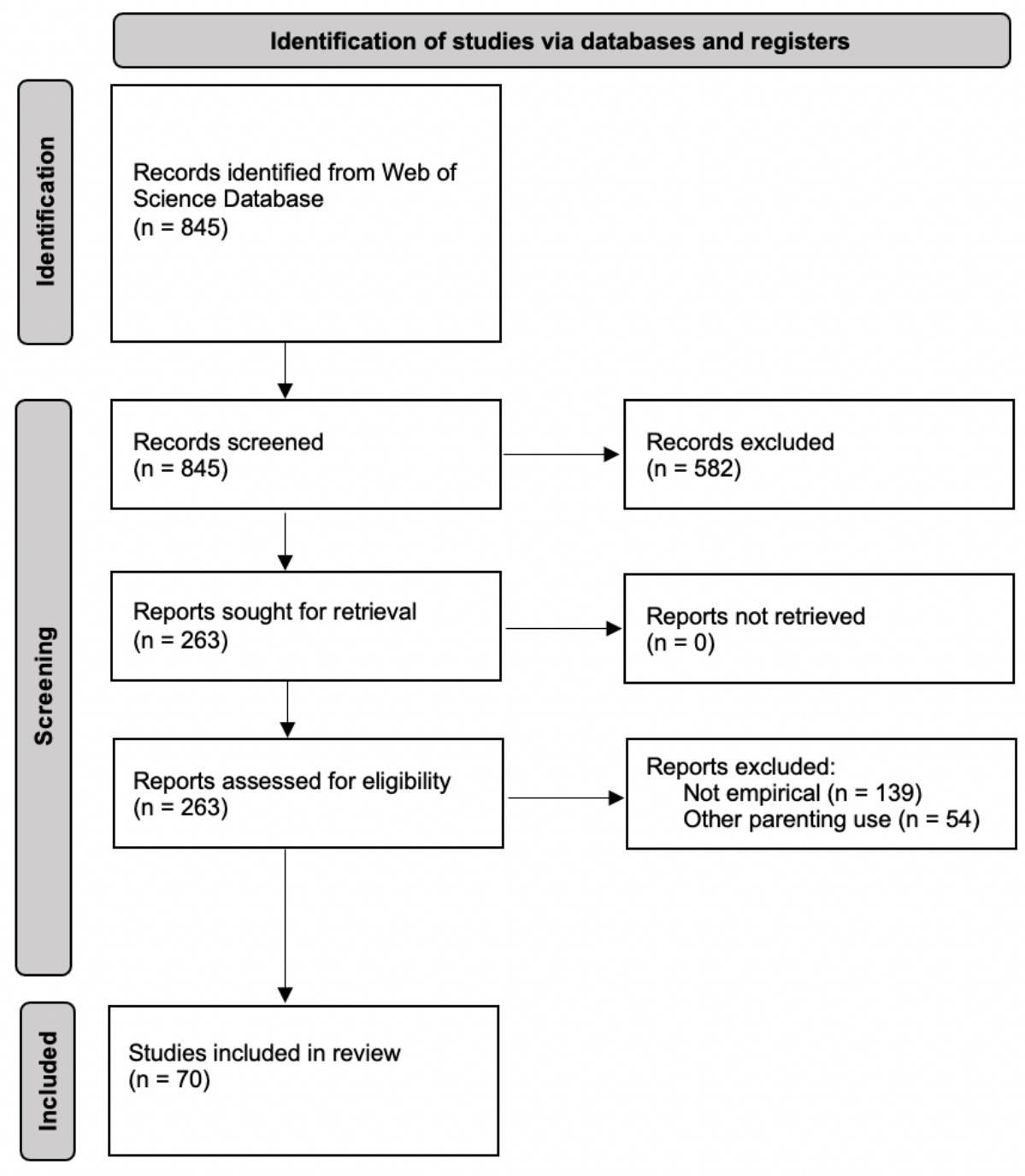

Figure 1. Overview of sampling procedure following PRISMA 2020 guidelines (Page et al., 2021)

\section{FINDINGS}

\subsection{Overview of Research Trends}

Findings show that publications about parent social media use have steadily risen since 2015 (see Figure 2), and that trajectory is expected to continue to increase. Of the 70 articles in the sample, $49(70 \%)$ of the articles were situated in the United States. An additional 5 were situated in Canada, and the remaining 16 were from Australia (3), the UK (2), Israel (2), Germany, Italy, Lebanon, South Africa, Switzerland, Taiwan, and Turkey. Twelve of these articles from outside North America were from 2019, the last year included in this study, and two were from 2018. This shows how interest in this research area has increased globally. 
Publication trajectory by category (2011-2019)

Publication about parents' use of social media related to parenting has increased over time across the categories

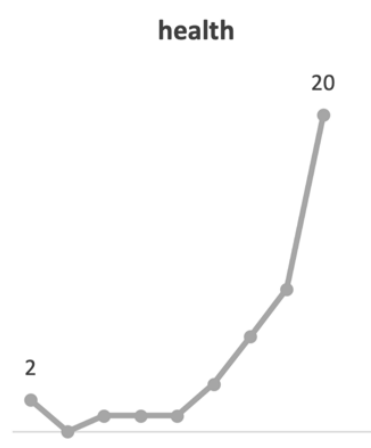

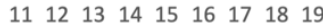

school

parenting support

other

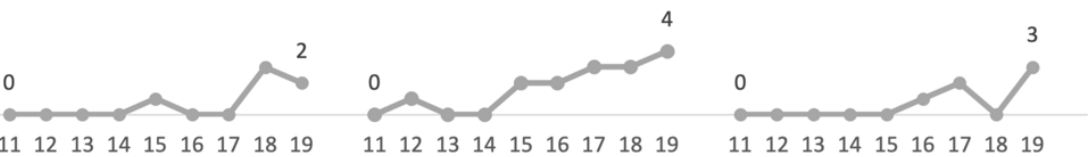

Figure 2. Publication trajectory by category across years

In terms of participants, all 70 studies had parents as research participants, and 4 studies (5.7\%) also included children as participants. When specific child age groups were specified, parents of younger children (age 0-4) were the most common participants, with $32(46 \%)$ of the studies focusing on them. None of the studies focused on parents of adult children.

Surveys were the most common form of data collection, followed by social media archives, and interviews (See Figure 3). Survey and interview methods were commonly used to collect data about parents' social media habits and attitudes (Barton et al., 2019), their interest in using new resources (Swindle et al., 2014) or their perceptions of existing social media resources (Külhaş Çelik et al., 2019), and their actions after encountering social media information resources (Hwang \& Shah, 2019). In contrast, social media archives were used to conduct content analyses of parents' online conversations and the resources they use. Through these content analysis, researchers explored issues such as the quality and accuracy of parenting content online (Kallem et al., 2018; Turner et al., 2011) and the nature of support and interactions offered to parents online (Zhao et al., 2019).

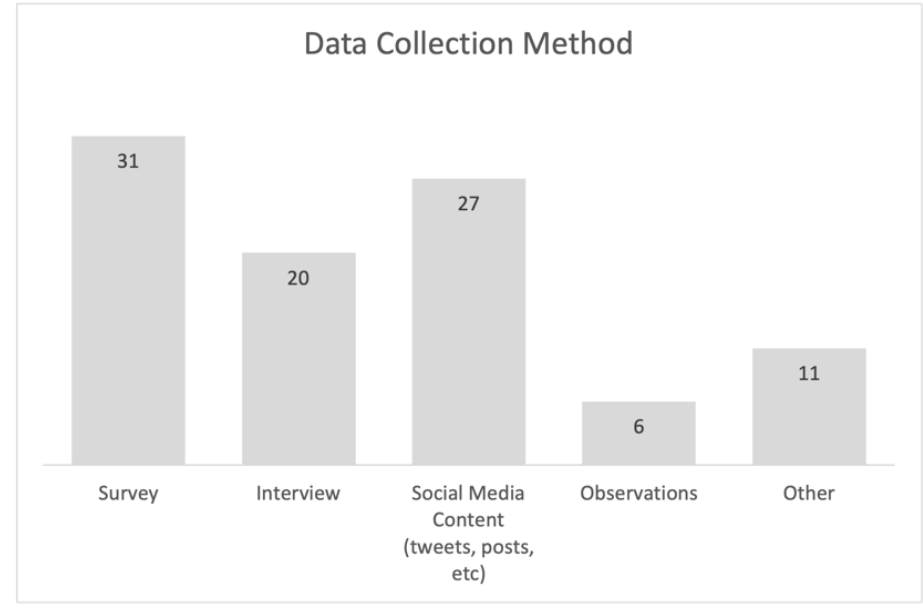

Figure 3. Data Collection Method 


\subsection{Social Media Use to Support Parenting}

Three main categories of research were apparent among the studies. Most prominent was research on parenting in a health-related context (see Figure 2). This category represented $44(62.9 \%)$ of the studies. More general parenting support research comprised 15 articles (21.4\%), and finally six studies (8.6\%) focused on school-related support. Five studies stood alone, not fitting in a category with other studies.

\subsubsection{Health-related Uses}

Parents use social media to access information about a diverse array of health-conditions, ranging from the general topics such as healthy behaviors (Laws et al., 2019) to specific health conditions like leukemia (Gage-Bouchard et al., 2017). These two articles investigate differences in who accesses health-related information online (Laws et al., 2019) and how social media spaces can unite parents with others who have similar parenting experiences for mutual information-sharing and support (Gage-Bouchard et al., 2017). Among the health-related parenting articles, one health topic stands out: vaccination. Vaccination rates are a public health concern, and social media has been a space where anti-vaccination groups have frequently spread misinformation. Articles in this area explored the nature and quality of information parents encounter in social media spaces along with how this information shapes their vaccination decisions for their children (Deas et al., 2019; Modanloo et al., 2019).

\subsubsection{General Parenting Support}

Most of the general parenting support articles focused on parenting of young children or parenting concerns prior to giving birth. They include studies about mommybloggers (Steiner \& Bronstein, 2017) and parenting groups (Das, 2019), demonstrating the powerful influence of stories shared online. Many of these articles are closely related to the health-related articles, with the main difference being the locus of information. Whereas health-related parenting support involves accessing information about health conditions from medical professionals or crowdsourcing health information with parents who have shared experiences caring for children with medical conditions, the general parenting support articles are situated in spaces where parents gather for camaraderie and to find other parents with similar philosophies and life choices. These studies explore how parents use social media to share their stories and perform their personal choices about birthing and raising children. Topics raised in the general parenting support category may touch on issues like mental health, but in the sense that participation on parenting forums may affect a parent's mental health (McDaniel et al., 2012).

\subsubsection{School-related Parenting Uses}

The six articles related to parenting and schools included two Israeli studies and one American study of how parents used social media as a leveraging tool for protest (Addi-Raccah \& Yemini, 2018; Avigur-Eshel \& Berkovich, 2018; Schroeder et al., 2018). Two others looked at social media as a tool for facilitating parent-school communications (Fan \& Yost, 2018; Vigo-Arrazola \& Dieste-Gracia, 2018). The final article examined how social media was used to gather information during a school crisis (Mazer et al., 2015). Collectively these six articles show how parents find alternate between using social media to have a voice and to gather information about school events and topics.

\section{DISCUSSION}

The heavy emphasis on health-related parenting support in social media settings was not a surprising finding. A recent literature review about social media use by healthcare providers similarly identified health care promotion and education as important uses of the medium (Farsi, 2021). Based on this literature, it appears that both parties - parents and medical professionals - have a mutual interest in maintaining online forums with accurate information and support for children's healthcare needs. Vaccination-focused studies aside, most of these articles investigate health conditions and communities in isolation. Pooling their knowledge across conditions and communities, researchers could help health professionals better meet their patients' needs by fostering helpful, positive online support spaces and identifying appropriate levels of their presence and intervention in these environments. A key takeaway from this collection of studies is that it is important 
to find a balance between accurate information and peer interaction. Parents seek these online spaces because they provide alternate perspectives and often a broader view than their own healthcare providers. Social media cannot treat their children, and the risk of misinformation is always present, but at the same time parents are pooling knowledge and learning from each other, often yielding positive outcomes.

Through this pooling of knowledge and collective learning, whether discussing health topics or parenting more generally, a lot of personal sharing takes place in online forums. This sharing may be done in the interest of supporting parents or meeting children's health needs, but at the same time it potentially makes families vulnerable. Parenting online raises concerns about children's privacy and digital footprints, affecting them before they are born (Seko \& Tiidenberg, 2016) or go on the Internet themselves (Dennen, 2016). This phenomenon of discussing one's children online has been dubbed sharenting and is often engaged in naively, with little consideration of the potential perils (Cino \& Formenti, 2021). Although parents do it freely, they may object when others, like teachers and schools, post about their children online (Cino \& Dalledonne Vandini, 2020). Given the personal nature of health information, more research on the risks within health-related parenting communities is warranted, including longitudinal studies to determine if any material or emotional harm has come to children through their parents' social media activities.

\subsection{Limitation}

A major limitation is the sampling approach used in this study. By focusing solely on the Web of Science database, the sample was not inclusive of international journals (Mongeon \& Paul-Hus, 2015). To some degree, this limitation was mitigated by our focus on English language journals. Additionally, we make no claim to provide a comprehensive overview of journal articles on our topic, but instead use Web of Science indexed journals as a proxy for overall research and publishing trends. Additionally, although this paper summarizes research trends and describes the types of parenting support that can be supported by social media, these trends should not be considered exhaustive or fully representative of the ways parents use social media as a tool to connect to other parents and gain information and support.

\section{CONCLUSION}

Twenty-first century parents have a powerful tool at their fingertips 24 hours a day: the Internet. Although the Internet is a vast and easily searchable digital library, it also is a space where two-way communication can occur and relationships can be fostered. For parents who may find that they have questions about child health and development, or who feel isolated and alone, social media can be alluring. A clear advantage of social media over static information sources is the ability to interact with others. Parents can either use their social media profiles to reach out to their regular networks, or use social media to make new contacts and discover communal virtual spaces inhabited by other parents with similar interests, needs, and experiences. Across the articles sampled in this study were instances of professionals (e.g., in healthcare or education) using social media to push information to and develop connections with parents; more experienced parents sharing with less experienced parents; and parents more generally developing community and sharing their stories with each other. Each of these approaches helps unite people and share information in more dynamic and flexible ways and build relationships that would likely not be possible if parents were constrained to interactions with people encountered through their physical networks.

The studies found in this review focus most heavily on parents of younger children and parents seeking health-related support. This could represent a greater need for online support among these groups, or it could represent targeted areas of interest within specific disciplines. Both parents of young children and parents of children with medical conditions are likely to interact with medical professionals about their children's' development milestones or health needs on a regular basis, and healthcare professionals are concerned about how social media can be used to provide accurate information and how misinformation spreads online as well. However, these findings should not be taken to mean that parents are most likely to seek social media-based parenting support when their children are young or have healthcare needs. We do not currently have an empirically supported depiction of how widespread the practice of seeking parenting support via social media is, nor of the platforms that best support these activities and the topical areas around which parents are most likely to connect. These areas constitute a research gap.

As can be seen by the publishing trends over time, this area is just beginning to blossom. The field would benefit from studies that help establish a baseline for understanding parent use of social media, in which the 
more specific and context-based studies included in this sample might be situated. Future research might focus on how parents use social media across their child-rearing years, considering how their needs for different types of information and support change as their children age and they become more secure as parents. Additionally, such research might look for differences in parenting social media behaviors between first time parents and more experienced parents. With a stronger sense of when and how parents seek support and build networks on social media, the field will have greater direction for specific sub-topics that might be investigated.

\section{ACKNOWLEDGEMENT}

We would like to thank the rest of the Students, Social Media \& Schools Research Team at Florida State University who helped as we began this project.

\section{REFERENCES}

Addi-Raccah, A., \& Yemini, M. (2018). What is up? Parental Whatsapp discussion groups in diverse educational settings in Israel. Multicultural Education Review, 10(4), 310-326. https://doi.org/10.1080/2005615x.2018.1532224

Arksey, H., \& O'Malley, L. (2005). Scoping studies: Towards a methodological framework. International Journal of Social Research Methodology, 8(1), 19-32. https://doi.org/10.1080/1364557032000119616

Avigur-Eshel, A., \& Berkovich, I. (2018). Who "likes' public education: Social media activism, middle-class parents, and education policy in Israel. British Journal of Sociology of Education, 39(6), 844-859. https://doi.org/10.1080/01425692.2017.1418294

Barton, K. S., Wingerson, A., Barzilay, J. R., \& Tabor, H. K. (2019). "Before Facebook and before social media...we did not know anybody else that had this": Parent perspectives on internet and social media use during the pediatric clinical genetic testing process. J Community Genet, 10(3), 375-383. https://doi.org/10.1007/s12687-018-0400-6

Chen, G. M. (2013). Don't call me that: A techno-feminist critique of the term mommy blogger. Mass Communication and Society, 16(4), 510-532. https://doi.org/10.1080/15205436.2012.737888

Cino, D., \& Dalledonne Vandini, C. (2020). "Why does a teacher feel the need to post my kid?": Parents and teachers constructing morally acceptable boundaries of children's social media presence. International Journal Of Communication, 14. https://ijoc.org/index.php/ijoc/article/view/12493

Cino, D., \& Formenti, L. (2021). To share or not to share? That is the (social media) dilemma. Expectant mothers questioning and making sense of performing pregnancy on social media. Convergence: The International Journal of Research into New Media Technologies, 27(2), 491-507. https://doi.org/10.1177/1354856521990299

Das, R. (2019). The mediation of childbirth: 'Joyful' birthing and strategies of silencing on a Facebook group. European Journal of Cultural Studies, 22(5-6), 495-510.

Deas, J., Bean, S. J., Sokolovska, I., \& Fautin, C. (2019). Childhood vaccine attitudes and information sources among Oregon parents and guardians. Health Promot Pract, 20(4), 529-538. https://doi.org/10.1177/1524839918778830

Dennen, V. P. (2016). Digital by default: Growing into your digital footprint. In P. G. Nixon, R. Rawal, \& A. Funk (Eds.), Digital media usage across the life course (pp. 67-83). Routledge.

Dennen, V. P., Choi, H., \& Word, K. (2020). Social media, teenagers, and the school context: A scoping review of research in education and related fields. Educational Technology Research and Development, 68, 1635-1658. https://doi.org/10.1007/s11423-020-09796-z

Duggan, M., Lenhart, A., Lampe, C., \& Ellison, N. B. (2015). Parents and social media. https://www.pewresearch.org/internet/2015/07/16/parents-and-social-media/

Dworkin, J., Connell, J., \& Doty, J. (2013). A literature review of parents' online behavior. Cyberpsychology: Journal of Psychosocial Research on Cyberspace, 7(2). https://doi.org/https://doi.org/10.5817/CP2013-2-2

Fan, S., \& Yost, H. (2018). Keeping connected: Exploring the potential of social media as a new avenue for communication and collaboration in early childhood education. International Journal of Early Years Education, 27(2), 132-142. https://doi.org/10.1080/09669760.2018.1454301

Farsi, D. (2021). Social media and health care, part I: Literature review of social media use by health care providers. $J$ Med Internet Res, 23(4), e23205. https://doi.org/10.2196/23205

Gage-Bouchard, E. A., LaValley, S., Mollica, M., \& Beaupin, L. K. (2017). Communication and exchange of specialized health-related support among people with experiential similarity on Facebook. Health Communication, 32(10), 1233-1240. https://doi.org/10.1080/10410236.2016.1196518

He, Y., \& Dworkin, J. (2015/2016). Cyber dads: What are fathers doing online? Fathering, 13(3), 219-230. https://doi.org/10.3149/fth.1303.219 
Hwang, J., \& Shah, D. V. (2019). Health information sources, perceived vaccination benefits, and maintenance of childhood vaccination schedules. Health Communication, 34(11), 1279-1288. https://doi.org/10.1080/10410236.2018.1481707

Jang, J., \& Dworkin, J. (2012). Babycenter.com: New parent behavior in an online community. The Forum for Family and Consumer Issues, 17(2), 1-14.

Kallem, S., Gruver, R. S., Virudachalam, S., \& Fiks, A. G. (2018). Mothers' Facebook posts about infant health: Findings from the Grow2Gether study. BMC Pediatrics, 18, 8, Article 341. https://doi.org/10.1186/s12887-018-1315-4

Külhaş Çelik, İ., Büyüktiryaki, B., Civelek, E., \& Kocabaş, C. N. (2019). Internet use habits of parents with children suffering from food allergy. Asthma Allergy Immunology, 17(3), 134-139. https://doi.org/10.21911/aai.485

Laws, R., Walsh, A. D., Hesketh, K. D., Downing, K. L., Kuswara, K., \& Campbell, K. J. (2019). Differences between mothers and fathers of young children in their use of the Internet to support healthy family lifestyle behaviors: Cross-sectional study. J Med Internet Res, 21(1), e11454. https://doi.org/10.2196/11454

Li, K., Rollins, J., \& Yan, E. (2018). Web of Science use in published research and review papers 1997-2017: A selective, dynamic, cross-domain, content-based analysis. Scientometrics, 115(1), 1-20. https://doi.org/10.1007/s11192-017-2622-5

Mazer, J. P., Thompson, B., Cherry, J., Russell, M., Payne, H. J., Kirby, E. G., \& Pfohl, W. (2015). Communication in the face of a school crisis: Examining the volume and content of social media mentions during active shooter incidents. Computers in Human Behavior, 53, 238-248. https://doi.org/10.1016/j.chb.2015.06.040

McDaniel, B. T., Coyne, S. M., \& Holmes, E. K. (2012). New mothers and media use: Associations between blogging, social networking, and maternal well-being. Maternal and Child Health Journal, 16(7), 1509-1517. https://doi.org/10.1007/s10995-011-0918-2

Modanloo, S., Stacey, D., Dunn, S., Choueiry, J., \& Harrison, D. (2019). Parent resources for early childhood vaccination: An online environmental scan. Vaccine, 37(51), 7493-7500. https://doi.org/10.1016/j.vaccine.2019.09.075

Mongeon, P., \& Paul-Hus, A. (2015). The journal coverage of Web of Science and Scopus: A comparative analysis. Scientometrics, 106(1), 213-228. https://doi.org/10.1007/s11192-015-1765-5

Morris, M., Boruff, J. T., \& Gore, G. C. (2016). Scoping reviews: Establishing the role of the librarian. J Med Libr Assoc, 104(4), 346-354. https://doi.org/10.3163/1536-5050.104.4.020

Page, M. J., Moher, D., Bossuyt, P. M., Boutron, I., Hoffmann, T. C., Mulrow, C. D., Shamseer, L., Tetzlaff, J. M., Akl, E. A., Brennan, S. E., Chou, R., Glanville, J., Grimshaw, J. M., Hrobjartsson, A., Lalu, M. M., Li, T., Loder, E. W., Mayo-Wilson, E., McDonald, S., McGuinness, L. A., Stewart, L. A., Thomas, J., Tricco, A. C., Welch, V. A., Whiting, P., \& McKenzie, J. E. (2021). PRISMA 2020 explanation and elaboration: updated guidance and exemplars for reporting systematic reviews. BMJ, 372, n160. https://doi.org/10.1136/bmj.n160

Peters, M. D., Godfrey, C. M., Khalil, H., McInerney, P., Parker, D., \& Soares, C. B. (2015). Guidance for conducting systematic scoping reviews. Int $J$ Evid Based Healthc, 13(3), 141-146. https://doi.org/10.1097/XEB.0000000000000050

Pham, M. T., Rajic, A., Greig, J. D., Sargeant, J. M., Papadopoulos, A., \& McEwen, S. A. (2014). A scoping review of scoping reviews: Advancing the approach and enhancing the consistency. Res Synth Methods, 5(4), 371-385. https://doi.org/10.1002/jrsm.1123

Schroeder, S., Currin, E., \& McCardle, T. (2018). Mother tongues: The Opt Out movement's vocal response to patriarchal, neoliberal education reform. Gender and Education, 30(8), 1001-1018. https://doi.org/10.1080/09540253.2016.1270422

Seko, Y., \& Tiidenberg, K. (2016). Birth through the digital womb. In P. G. Nixon, R. Rawal, \& A. Funk (Eds.), Digital media usage across the lifecourse (pp. 50-66). Routledge.

Steiner, L., \& Bronstein, C. (2017). Leave a comment: Mommyblogs and the everyday struggle to reclaim parenthood. Feminist Media Studies, 17(1), 59-76. https://doi.org/10.1080/14680777.2017.1261840

Swindle, T. M., Ward, W. L., Whiteside-Mansell, L., Bokony, P., \& Pettit, D. (2014). Technology use and interest among low-income parents of young children: Differences by age group and ethnicity. Journal of Nutrition Education and Behavior, 46(6), 484-490. https://doi.org/10.1016/j.jneb.2014.06.004

Tricco, A. C., Lillie, E., Zarin, W., O'Brien, K., Colquhoun, H., Kastner, M., Levac, D., Ng, C., Sharpe, J. P., Wilson, K., Kenny, M., Warren, R., Wilson, C., Stelfox, H. T., \& Straus, S. E. (2016). A scoping review on the conduct and reporting of scoping reviews. BMC Med Res Methodol, 16, 15. https://doi.org/10.1186/s12874-016-0116-4

Turner, A., Kabashi, A., Guthrie, H., Burket, R., \& Turner, P. (2011). Use and value of information sources by parents of child psychiatric patients. Health Information and Libraries Journal, 28(2), 101-109. https://doi.org/10.1111/j.14711842.2011.00935.x

Vigo-Arrazola, B., \& Dieste-Gracia, B. (2018). Building virtual interaction spaces between family and school. Ethnography and Education, 14(2), 206-222. https://doi.org/10.1080/17457823.2018.1431950

Zhao, Y., Zhang, J., \& Wu, M. (2019). Finding users' voice on social media: An investigation of online support groups for autism-affected users on Facebook. Int $J$ Environ Res Public Health, 16(23). https://doi.org/10.3390/ijerph16234804 